JURNAL RISET REKAYASA ELEKTRO

Vol 3. No 2 Desember 2021, Hal 101 - 110

\title{
Sistem Peringatan Dini Bahaya Banjir Pada Daerah Aliran Irigasi
}

\author{
Ahmad Fauzan', Latiful Hayat ${ }^{2}$ \\ Program Studi S1 Teknik Elektro, Universitas Muhammadiyah Purwokerto \\ Fakultas Teknik dan Sains, Universitas Muhammadiyah Purwokerto
}

\section{Informasi Makalah}

Dikirim, 21 Agustus 2021

Direvisi, 16 Desember 2021

Diterima, 17 Desember 2021

\section{Kata Kunci:}

IOT

ESP8266

Android

\begin{abstract}
INTISARI
Bencana banjir kerap melanda Indonesia pada beberapa tahun terakhir ini. Terjadinya banjir disuatu daerah mengakibatkan kerugian harta benda. Oleh karenanya, pemerintah memusatkan perhatian terhadap bencana banjir. Upaya untuk mengantisipasi banjir dapat berupa normalisasi dan naturalisasi sungai, waduk, dan embung, pembuatan sodetan dan sumur resapan, hingga penyiagaan pompa stasioner dan portabel. Solusi lain yang dapat diajukan, salah satunya adalah pembuatan sistem deteksi dini banjir. System ini diharapkan dapat memberi informasi kepada masyarakat sekitar dan tim SAR dalam penanganan bencana yang akan terjadi. Sistem monitoring dirancang agar aplikasi Android dapat memberikan informasi mengenai level ketinggian air melalui sensor water level. Dalam pembuatan monitoring, aplikasi yang digunakan adalah kodular.io. Ini berfungsi untuk menampilkan hasil dari pembacaan sensor yang dipasang dalam rangkaian terkoneksi dengan modul ESP8266, yakni pengirim data analog yang akan dirubah dalam sistem firebase. Pada penelitian ini berhasil dilakukan berbagai percobaan yaitu, percobaan dalam status level air $10 \mathrm{~cm}$ menampilkan status aman, pada percobaan $20 \mathrm{~cm}$ menunjukkan kondisi status siaga, dan percobaan yang terakhir yaitu dalam level $30 \mathrm{~cm}$ yang menunjukkan status pada level bahaya diikuti dengan pesan peringatan agar masyarakat segera evakuasi dini. Peringatan tentang status ketinggian air berupa aman dan waspada juga dikirimkan melalui pesan dari aplikasi Android menggunakan ESP8266. ESP8266 difungsikan sebagai IOT pengirim pesan peringatan ke aplikasi pengguna.
\end{abstract}

\begin{abstract}
Flood is one of the disasters that often-hit Indonesia in recent years. The occurrence of flooding in an area result in property loss. Therefore, the government focuses on flood disasters. Efforts to anticipate flooding, such as normalizing and naturalizing rivers, reservoirs, and reservoirs, constructing drains and infiltration wells, to preparing stationary and portable pumps have been carried out. Another solution that can be proposed, one of which is the creation of an early flood detection system. A flood detection system using an Android application interface is a tool that can provide water level information to determine flooding potential. A water level sensor is used as a tool to measure the water level. It uses the kodular.io application, which will later display the results of the sensor readings installed in a circuit connected to the ESP8266 module. The module acts as a sender of analogue data, and the data will be store in the firebase system. In this study, the author succeeded in conducting various experiments. Based on research when the water level was $10 \mathrm{~cm}$ is a safe status. When the water level was $20 \mathrm{~cm}$, it showed the standby status. When the water level was $30 \mathrm{~cm}$, it showed a dangerous status level followed by a warning message. Thus, the community can evacuate immediately. The system can also provide warnings about high water levels when safe, warning, and dangerous. It will be able to send warning messages through the Android application by using applications installed in it.
\end{abstract}

\section{Korespondensi Penulis:}

Ahmad Fauzan

Program Studi Teknik Elektro

Fakultas Teknik dan Sains Universitas Muhammadiyah Purwokerto

JL. Raya Dukuhwaluh, Purwokerto, 53182

Email: ojan941gmail.com 


\section{PENDAHULUAN}

Bencana banjir kerap melanda Indonesia pada beberapa tahun terakhir ini. Oleh karenanya, pemerintah memusatkan perhatian terhadap bencana banjir. Pemerintah mengambil peran melalui Badan Nasional Penanggulangan Bencana (BNPB) sebagai salah satu badan berperan menanggulangi bencana alam di Indonesia termasuk banjir. Dalam kasus bencana banjir banyak menyebabkan kerugian. Tidak hanya menelan korban jiwa, banjir juga mengakibatkan kerugian harta benda. Berdasarkan data dari BNPB, awal Januari sampai Agustus tahun 2020 kurang lebih 100 jiwa meninggal dunia akibat banjir. BNPB juga mencatat 726 dari 2,8 juta jiwa orang mengungsi. Adapun kerugian yang terjadi pada sektor perumahan tercatat sebanyak 4.581 unit rusak parah, 2.784 rusak sedang, 9.833 mengalami rusak ringan serta rumah yang teredam sebanyak 540.739. Bencana banjir juga berimbas pada kerusakan infrastruktur fasilitas umum seperti fasilitas pendidikan 496 unit, peribadatan 581, kesehatan 112, perkantoran 109 dan jembatan sebanyak 299 [1].

Mengingat permasalahan banjir di Indonesia belum terselesaikan secara tuntas, bahkan adanya indikasi peningkatan mencakup intensitas, frekuensi dan persebaran ke ruangannya. Berdasarkan acuan perkiraan BMKG, diprediksi sekitar 90 persen dari kejadian merupakan bencana hidrometeorologi seperti banjir, longsor, hingga puting beliung. Hal ini disebabkan oleh kondisi lingkungan yang darurat ekologis, di mana terjadi kerusakan lingkungan, degradasi hutan, serta Daerah Aliran Sungai (DAS) yang kritis sehingga membuat bencana banjir meluas [2].

Langkah yang perlu diupayakan dalam menghadapi bencana banjir adalah normalisasi dan naturalisasi sungai, waduk, dan embung, pembuatan sodetan dan sumur resapan, hingga penyiagaan pompa stasioner dan portable. Upaya lain yang dapat dilakukan adalah memasang alat pendeteksi dini. Pendeteksi dini bahaya banjir dinilai berguna untuk meminimalisir korban jiwa dan kerugian harta benda [3]. Alat ini digunakan untuk memantau pasang surut aliran air. Sistem pendeteksi banjir bekerja secara otomatis dengan mengetahui elevasi (ketinggian) permukaan air menggunakan sensor ultrasonic [7]. Adapun air pasang dapat dipengaruhi oleh kelembapan di sekitar aliran sungai. Pada saat suhu dan kelembapan tinggi, maka dapat disimpulkan hujan akan turun dan mengakibatkan air pasang sehingga berpotensi banjir. Deteksi dini banjir dapat menggunakan sensor curah hujan atau Rain Sensor Module.[4]

Latar belakang yang telah dipaparkan di atas menjadi bahan penelitian pada penelitian ini. Penelitian ini menggunakan metode pembacaan ketinggian air untuk mendeteksi bahaya datangnya banjir. Pada penelitian ini dirancang agar ketinggian air dapat dimonitor menggunakan aplikasi Android berdasar sensor water level. Adapun lokasi penelitiannya adalah aliran irigasi yang terletak di Banyumas, Jawa Tengah. Pasalnya, dilansir dari kompas.com, aliran sungai Serayu kembali meluap dan menyebabkan banjir setelah 20 terakhir tidak terjadi banjir tepatnya tahun 2000 .

\section{METODE PENELITIAN}

\subsection{Alur Penelitian}

Pembuatan penelitian ini menggunakan sensor water level. Pada pengaplikasiannya sensor water level digunakan untuk mengukur ketinggian air. Adapun jarak pengukuran yang dilakukan dalam sistem monitoring banjir adalah jarak aman pada $10 \mathrm{~cm}$, jarak siaga $20 \mathrm{~cm}$, dan jarak bahaya pada angka $30 \mathrm{~cm}$. Sensor water level di sini hanya akan bekerja jika permukaan sensor mengenai air yang akan terbaca secara analog dan akan dikonversikan kedalam digital melalui mikrokontroller NodeMCU. Pada sistem ini, sensor water level menjadi input menuju NodeMCU ESP8266. ESP8266 memiliki integrasi konektivitas Wifi sehingga memudahkan untuk koneksi data nirkabel. Data yang dihasilkan dari pemrosesan NodeMCU ESP8266 diunggah melalui internet menuju firebase. Data juga ditampilkan pada LCD 16x2 dalam bentuk Informasi agar dapat dimonitoring secara langsung di lokasi tanpa membutuhkan koneksi internet.

Sistem monitoring banjir ini menggunakan aplikasi berbasis android yang berfungsi sebagai pemantau informasi yang diperoleh darimanapun melalui aplikasi android yang telah dibuat. Adapun pemrograman menggunakan Arduino IDE karena dapat mengatur beberapa kondisi input agar tidak terjadi kesalahan. Selanjutnya program diupload menuju NodeMCU ESP8266 yaitu modul pendukung Internet of Things (IoT). Alur penelitian ditunjukan pada Gambar 1, berikut ini: 


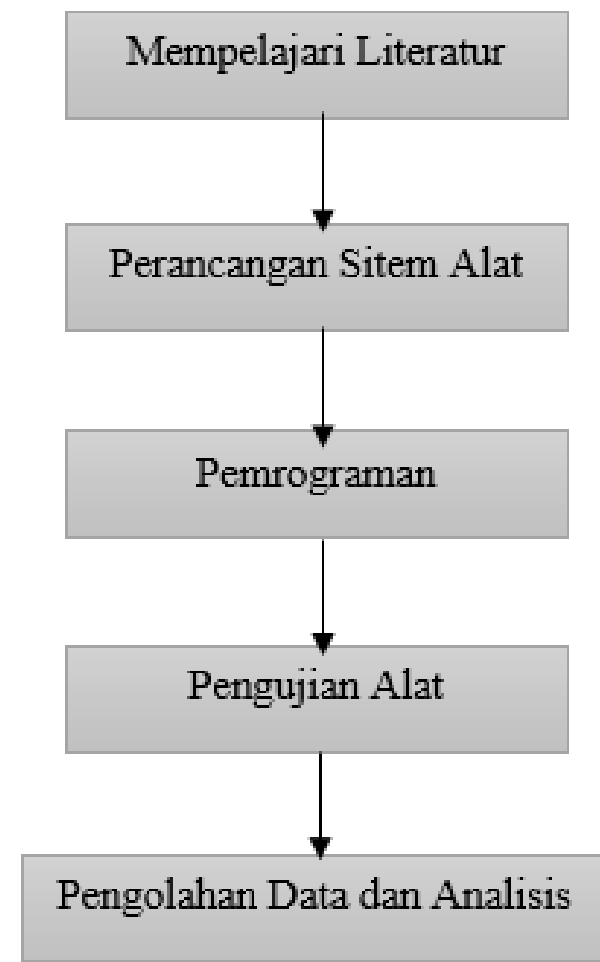

Gambar 1. Alur Penelitian

2.2. Perancangan sistem

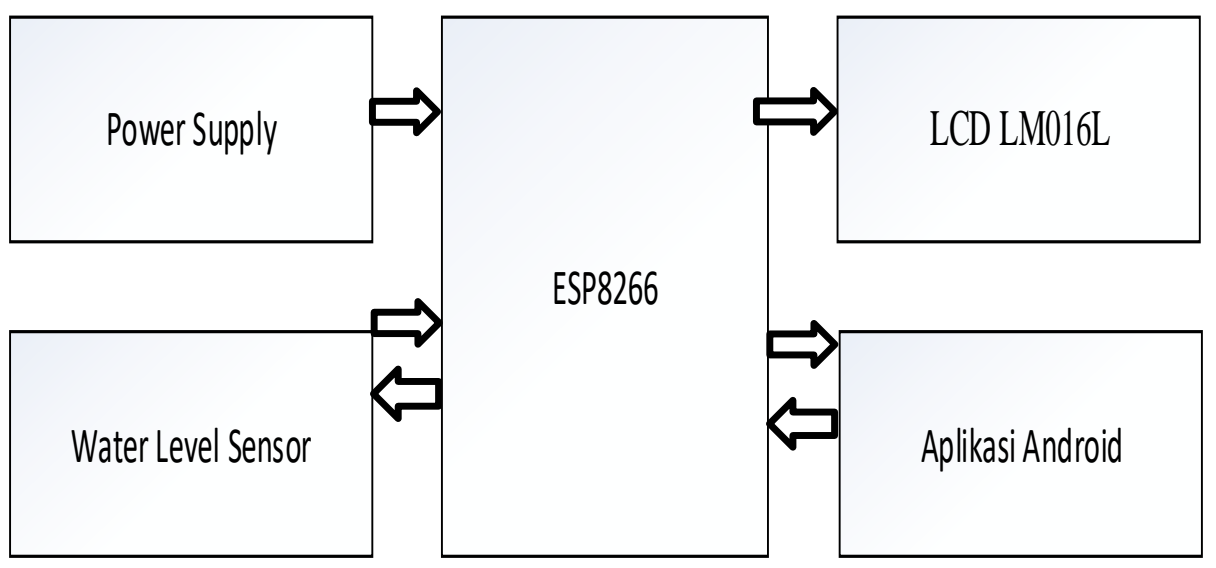

Gambar 2. Diagram Blok sistem 


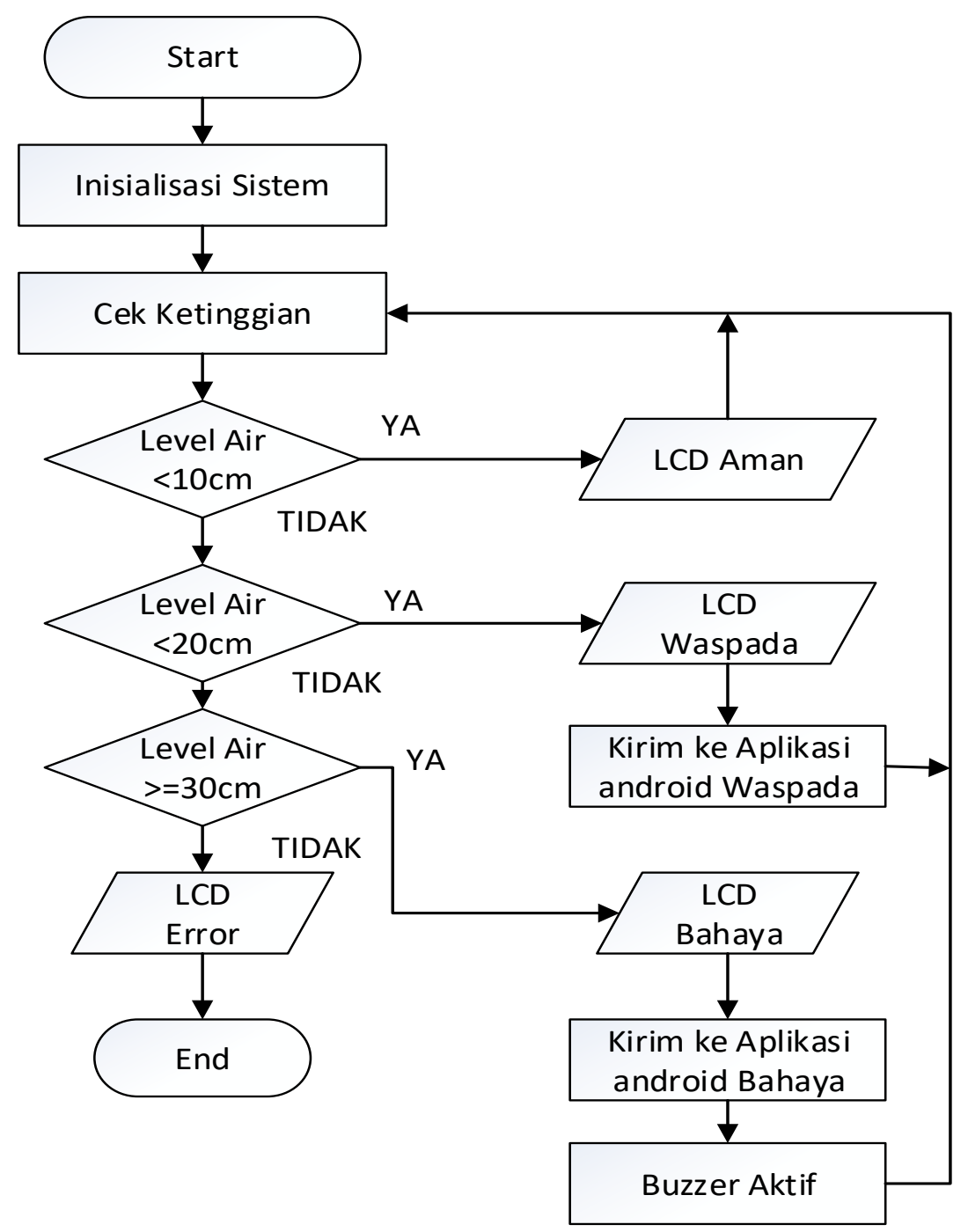

Gambar 3 Diagram Flowchart sistem

Flowchart cara kerja alat dari pembacaan data dari sistem web ke Aplikasi android kemudian, penampil LCD dan buzzer sampai dengan pembacaan pada aplikasi Android, seperti yang ditunjukan pada Gambar 3. Langkah pertama yaitu. Start inisialisasi sistem kemudian cek ketinggian ketika pada status level air pada jarak $10 \mathrm{~cm}$, maka akan tertampil pada layar monitor lcd pada status aman. Selanjutnya cek ketinggian ketika level air pada jarak $20 \mathrm{~cm}$ maka akan tertampil pada layar monitor LCD pada status waspada, dan dikirimkan pada aplikasi Android dalam status waspada. Kemudian cek ketiggian yang terakhir adalah pada status bahaya, ketika pada jarak $30 \mathrm{~cm}$ maka status level yang terbaca dan ditampilkan pada monitor lcd adalah dalam status level bahaya buzzer berbunyi, yang akan dikirimkan pada aplikasi android diikuti dengan pesan peringatan agar segera melakukan evakuasi segera ketempat yang lebih aman. Jika jarak melebihi $30 \mathrm{~cm}$ maka pembacaan yang terjadi pada LCD akan error. 


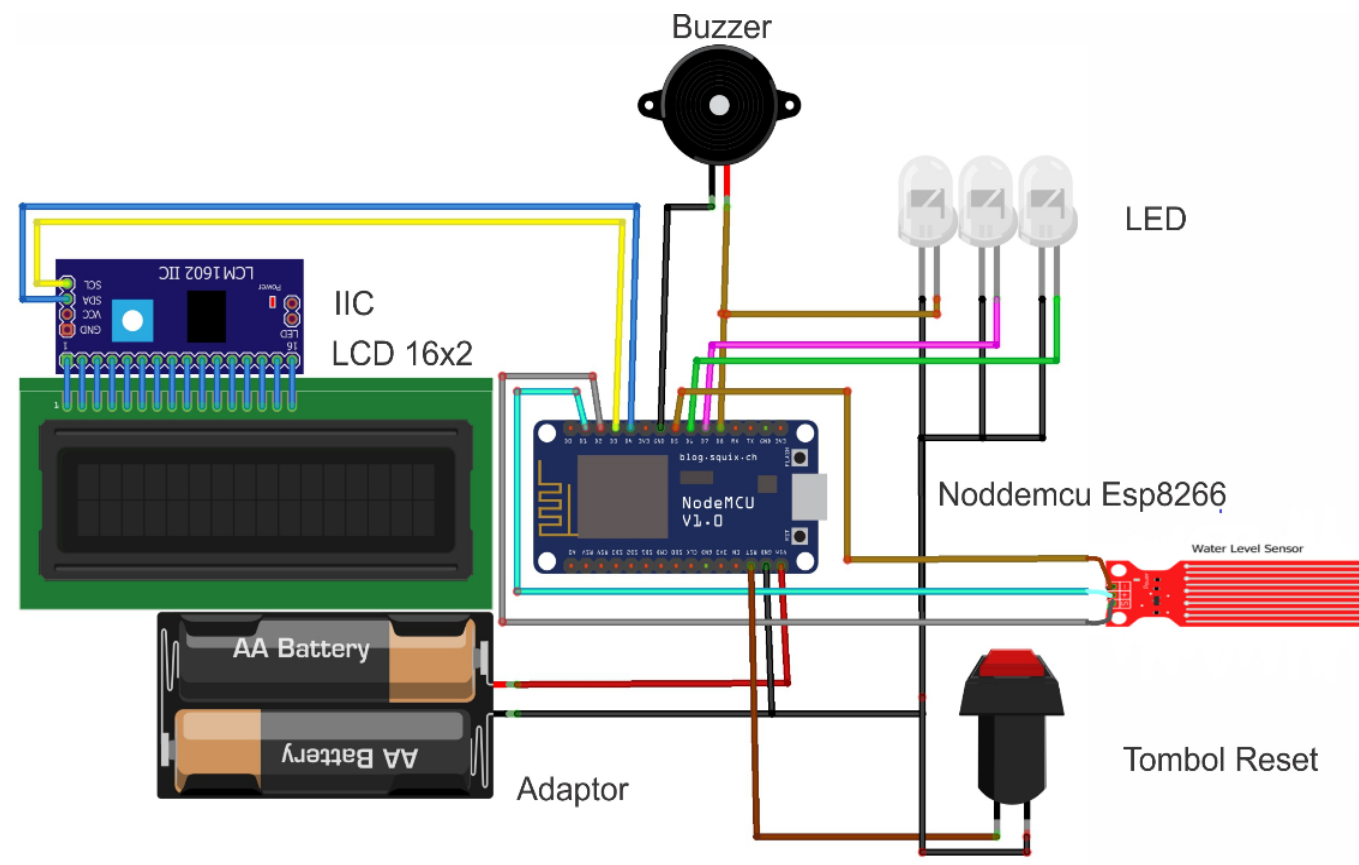

Gambar 4 Skema rangkaian monitoring banjir

Pada skema rangkaian sistem monitoring banjir, gambar rangkaian dibuat menggunakan software Fritzing. Di dalamnya terdapat library yang harus diunduh terlebih dahulu dari aplikasi maupun dari sumber lain seperti internet. Apabila library telah terunduh, maka pembuatan skema perancangan sistem dapat dilakukan. Ada beberapa langkah yang dibutuhkan yaitu menghubungkan seluruh pin VCC dan seluruh pin GND pada komponen rangkaian. Selanjutnya menghubungkan sensor water level menuju ke NodeMCU ESP8266, setelah itu menghubungkan I2C I/O LCD ke mikrokontroller NodeMCU ESP8266.

\section{HASIL DAN PEMBAHASAN}

Sistem monitoring banjir ini dapat diakses melalui smartphone android. Pada aplikasi android terdapat tampilan status ketinggian air pada status aman, siaga, dan bahaya yang diikuti dengan perubahan kenaikan grafik ketinggian air. Aplikasi android monitoring banjir ini akan bekerja jika mikrokontroller terhubung dengan wifi smartphone. Pada status level bahaya aplikasi android akan terus memberikan notifikasi peringatan "Status ketinggian air pada level bahaya! Segera lakukan evakuasi".

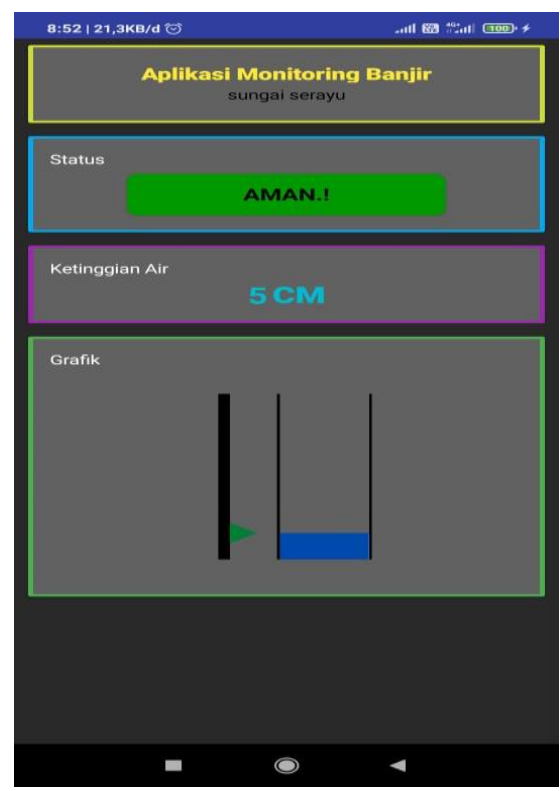

Gambar 5 Tampilan ketika status aman pada aplikasi monitoring banjir 


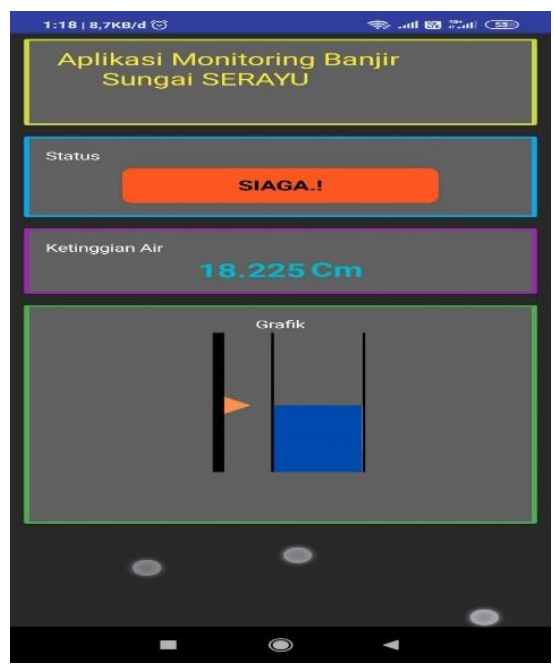

Gambar 6 Tampilan ketika status siaga pada aplikasi monitoring banjir

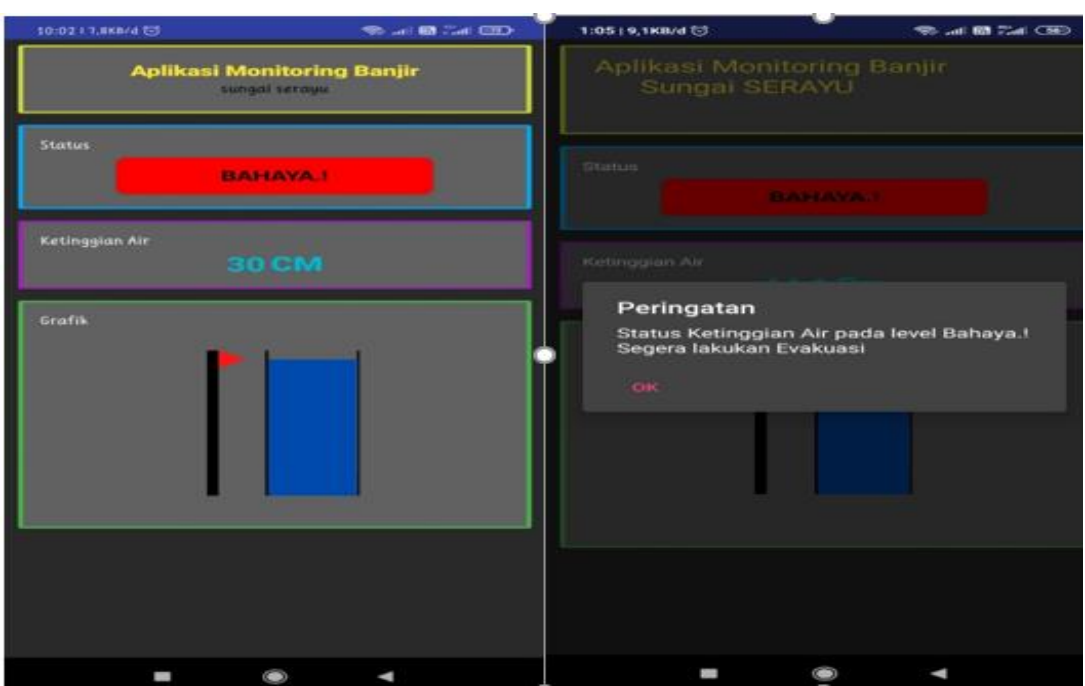

Gambar 7 Tampilan ketika status bahaya dan peringatan pada aplikasi monitoring banjir

Gambar 7 adalah tampilan dimana level ketinggian air pada level bahaya dan peringatan "Status Ketinggian Air pada level Bahaya.! Segera lakukan Evakuasi” pesan peringatan ini dibuat agar pengguna (masyarakat) dapat segera bergegas menyelamatkan diri dikarenakan status level air sudah dalam jarak bahaya. Status peringatan agar melakukan evakuasi akan terus muncul ketika kondisi air dalam level bahaya.

Tabel 1 Pengukuran power supply

\begin{tabular}{lc}
\hline \multicolumn{1}{c}{ Subyek } & $\begin{array}{c}\text { Hasil } \\
\text { Pengukuran }\end{array}$ \\
& \\
\hline Adaptor tanpa beban & $4,9 \mathrm{~V}$ \\
Adaptor dengan beban & $4,8 \mathrm{~V}$ \\
NodeMCU port tanpa beban & $4,9 \mathrm{~V}$ \\
NodeMCUport dengan beban & $4,8 \mathrm{~V}$ \\
\hline
\end{tabular}

Pada tabel 1 dilakukan pengukuran Power supply yang digunakan yaitu adaptor DC 5V. Pengujian dilakukan menggunakan multimeter pada mode selector DCV. Pengujian power supply dilakukan untuk memastikan agar tegangan tidak drop saat digunakan untuk memenuhi kebutuhan power seperti, NodeMCU, sensor water level, LCD, dan juga buzzer. 
Diambil sample hasil pengujian yang telah dilakukan percobaan seperti yang tertera pada Gambar 5 hingga gambar 7 yaitu sistem monitoring banjir pada level ketinggian tertentu. Untuk sample dari percobaan yang telah dilakukan dapat dilihat pada Tabel 1.

Tabel 2 Pengujian sensor water level

\begin{tabular}{|c|c|c|c|c|}
\hline $\begin{array}{l}\text { Pengujian } \\
\text { ke- }\end{array}$ & $\begin{array}{l}\text { Aktual Level Air } \\
(\mathrm{Cm})\end{array}$ & Pengukuran Alat $(\mathrm{Cm})$ & Rata- rata & $\begin{array}{c}\text { Error Sensor } \\
\%\end{array}$ \\
\hline 1 & \multirow{5}{*}{$\begin{array}{l}\text { Aman } \\
10 \mathrm{Cm}\end{array}$} & $10 \mathrm{Cm}$ & \multirow{5}{*}{$10 \mathrm{Cm}$} & \multirow{5}{*}{$0 \%$} \\
\hline 2 & & $10 \mathrm{Cm}$ & & \\
\hline 3 & & $10 \mathrm{Cm}$ & & \\
\hline 4 & & $10 \mathrm{Cm}$ & & \\
\hline 5 & & $10 \mathrm{Cm}$ & & \\
\hline 1 & \multirow{5}{*}{$\begin{array}{l}\text { Siaga } \\
20 \mathrm{Cm}\end{array}$} & $20 \mathrm{~cm}$ & \multirow{5}{*}{$20 \mathrm{Cm}$} & \multirow{5}{*}{$0 \%$} \\
\hline 2 & & $20 \mathrm{Cm}$ & & \\
\hline 3 & & $20 \mathrm{Cm}$ & & \\
\hline 4 & & $20 \mathrm{Cm}$ & & \\
\hline 5 & & $20 \mathrm{Cm}$ & & \\
\hline 1 & \multirow{5}{*}{$\begin{array}{l}\text { Bahaya } \\
\text { 30Cm }\end{array}$} & $30 \mathrm{~cm}$ & \multirow{5}{*}{$30 \mathrm{Cm}$} & \multirow{5}{*}{$0 \%$} \\
\hline 2 & & $30 \mathrm{Cm}$ & & \\
\hline 3 & & $30 \mathrm{Cm}$ & & \\
\hline 4 & & $30 \mathrm{Cm}$ & & \\
\hline 5 & & $30 \mathrm{Cm}$ & & \\
\hline
\end{tabular}

Pengujian dilakukan sebanyak 5 kali dengan, masing-masing jarak sensor dengan objek yaitu $10 \mathrm{~cm}$, $20 \mathrm{~cm}, 30 \mathrm{~cm}$. Cara menghitung nilai error pada pengukuran sensor adalah sebagai berikut :

Nilai error $=$ Jarak objek dengan sensor Rata-rata $\mathrm{x} 100 \%$ Jarak yang diinginkan

Contoh : error rata-rata ( \%) pada jarak $20 \mathrm{~cm}$ Nilai error $=20-20 \times 100 \% 20 \mathrm{~cm}=0 \%$

Dari hasil pengujian sebanyak 5 kali, menunjukkan bahwa sensor memiliki nilai error $0 \%$, atau dengan kata lain memiliki tingkat akurasi yang baik sebesar $100 \%$.

Tabel 3 Hasil Pengujian Tegangan

\begin{tabular}{ccc}
\hline NO. & $\begin{array}{c}\text { Jarak Ukur } \\
(\mathrm{cm})\end{array}$ & $\begin{array}{c}\text { Nilai Tegangan sensor } \\
(\text { Volt })\end{array}$ \\
\hline 1 & 0 & 3.33 \\
2 & 5 & 3.33 \\
3 & 10 & 3.27 \\
4 & 15 & 3.22 \\
5 & 20 & 3.19 \\
6 & 25 & 2.80 \\
7 & 30 & 2.82
\end{tabular}


Tabel 4 Hasil pengujian pada LCD

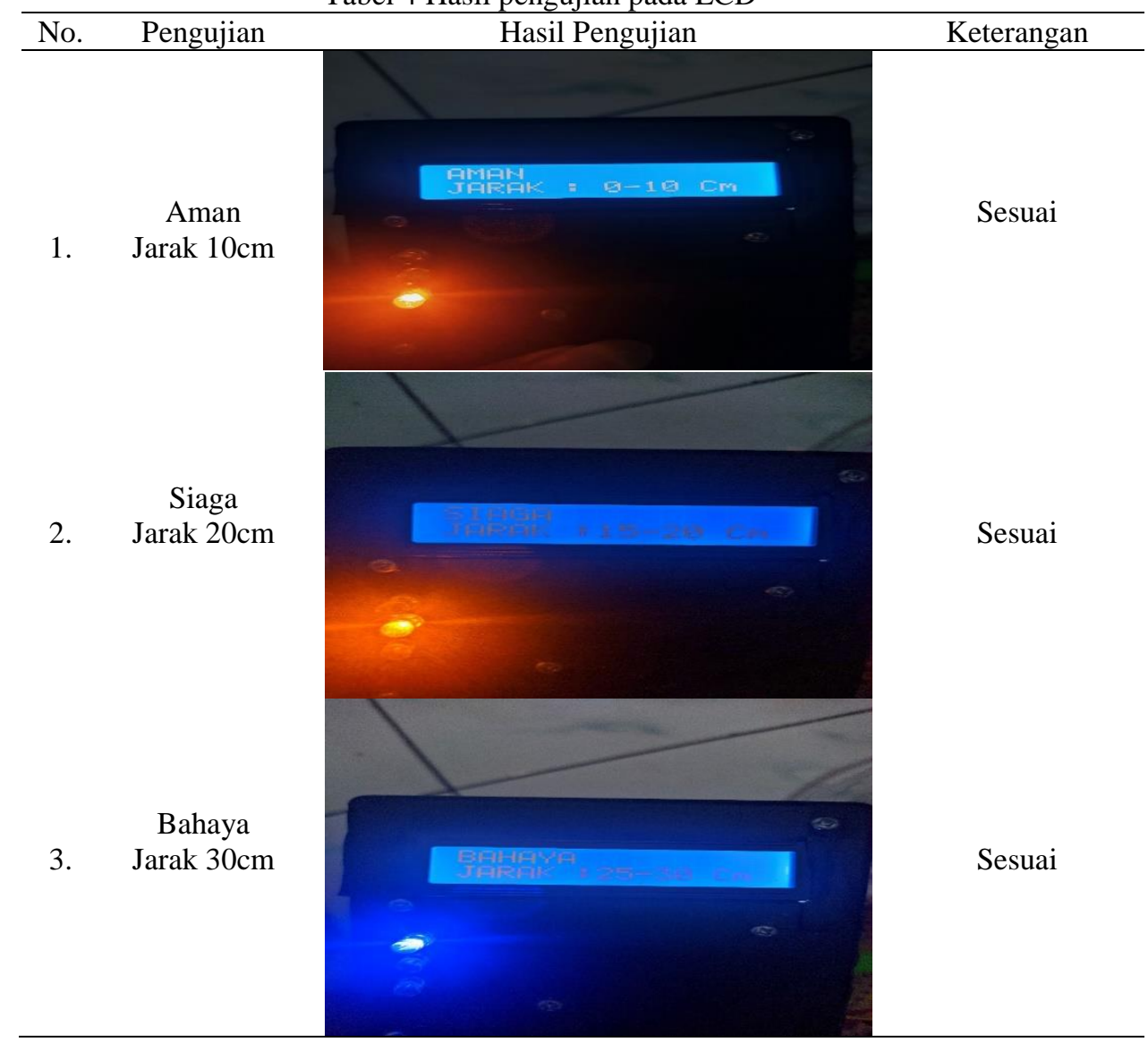

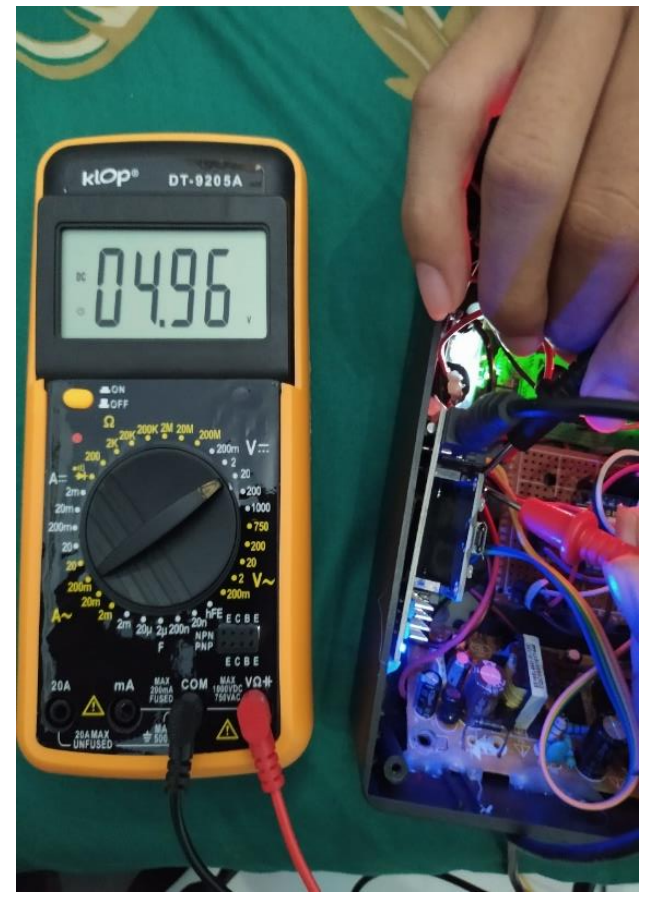

Gambar 8 Hasil Pengujian powe supply 


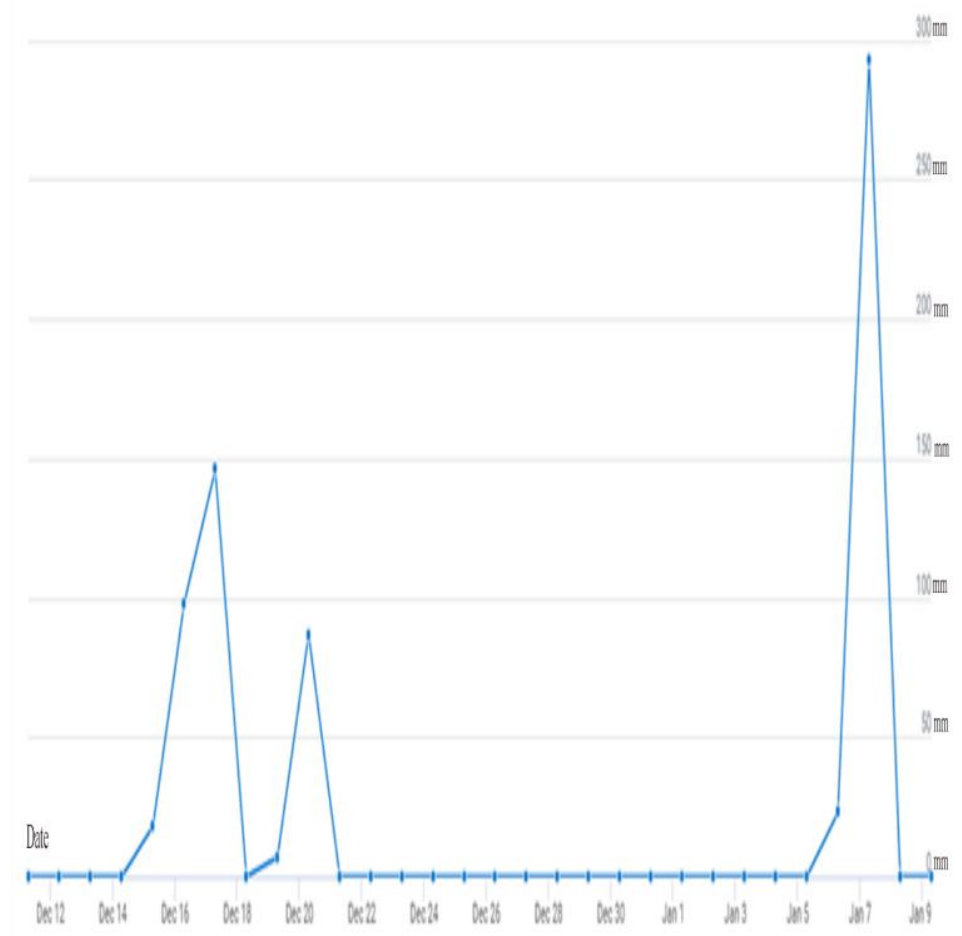

Gambar 9 Grafik hasil pengujian pada website

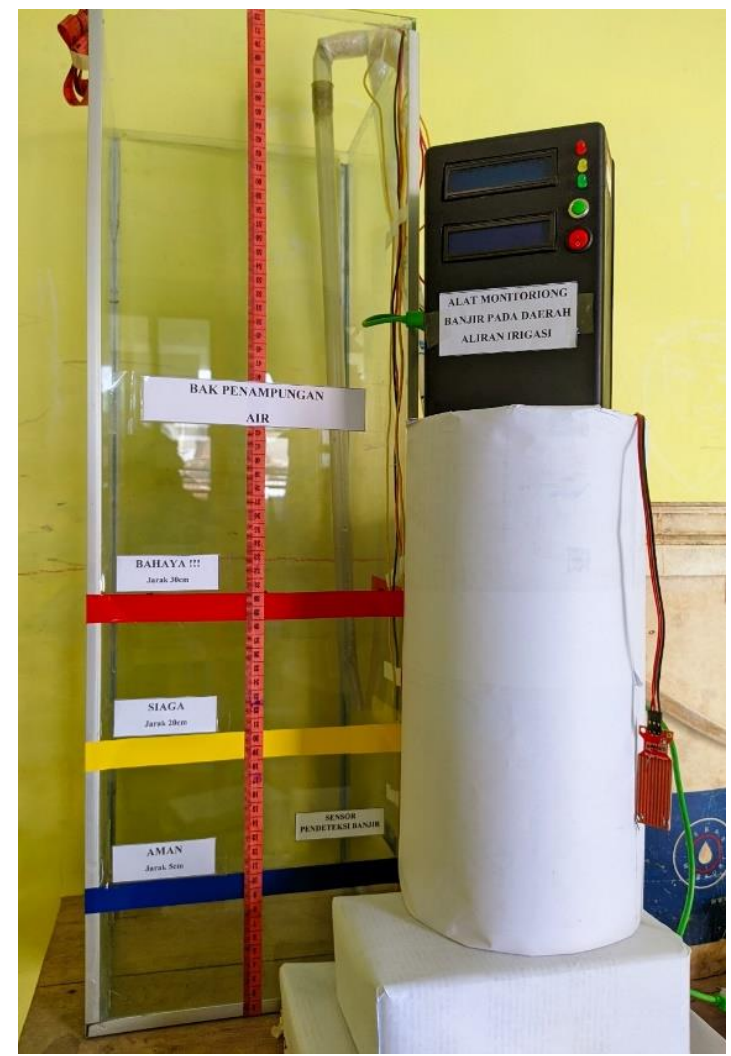

Gambar 10 Hasil keseluruhan alat monitoring banjir 


\section{KESIMPULAN}

Pembuatan sistem dalam penelitian ini telah berhasil. Sistem monitoring banjir dapat bekerja sesuai dengan perencanaan. Di mana sistem ini dapat mendeteksi ketinggian air dengan batasan jarak aman pada $10 \mathrm{~cm}$, jarak siaga $20 \mathrm{~cm}$, dan jarak bahaya $30 \mathrm{~cm}$. Serta dapat mengirimkan notifikasi peringatan status level bahaya agar segera lakukan evakuasi yang diikuti dengan alarm (buzzer) berbunyi. Apabila sensor dapat memproses data pada mikrokontroller NodeMCU ESP8266 dan disimpan pada Realtime Database, kemudian data dapat diunggah menuju aplikasi Android dan tampil pada LCD 16X2, maka sensor dan perangkat lainnya telah bekerja dengan baik dalam memberikan informasi dari kondisi aman hingga status level bahaya. Penelitian ini masih bisa dikembangkan sehingga disarankan untuk melakukan pengontrolan informasi pada sensor level air secara realtime menggunakan website online.

\section{UCAPAN TERIMAKASIH}

Ucapan terima kasih disampaikan kepada Keluarga Mahasiswa Teknik Elektro dan Dosen Teknik Elektro Universitas Muhammadiyah Purwokerto, yang telah memberikan dukungannya dalam penelitian ini.

\section{DAFTAR PUSTAKA}

[1] Akhiruddin, A. (2018). Rancang Bangun Alat Pendeteksi Ketinggian Air Sungai Sebagai Peringatan Dini Banjir Berbasis Arduino Nano. JET (Journal of Electrical Technology) ,3 (3), 174-179.

[2] Amin, A. (2018). Monitoring Water Level Control Berbasis Arduino Uno Menggunakan LCD LM016L. Jurnal EEICT (Electric, Electronic, Instrumentation, Control, Telecommunication), 1(1).

[3] Azid, S., Sharma, B., Ranghuwaiya, K., Chand, A., Prasad, S., \& Jacquier, A. (2015). SMS based flood monitoring and early warning system ARPN J. Eng. Appl. Sci, 10(15), 6387-6391

[4] Bando, S.A, Darlis, D., \& Aulia, S. (2016). Implementasi Perangkat Deteksi Dini Banjir Di Perumahan Permata Buah Batu Dengan Teknologi Internet Of Things. eProceedings of Applied Science.

[5] Jalil, A. (2017). Sistem kontrol deteksi level air pada media tanam hidroponik berbasis arduino uno. JURNAL IT, 8(2), 97-101.

[6] Rabbani, IM. (2018). Pengembangan Alat Deteksi Banjir Berbasis Metode Fuzzy. e-Proceeding of Engineering. Telkom University, 2355-9365.

[7] Umari, C., Anggraini, E., \& Muttaqin, R. Z. (2019). Rancang Bangun Sistem Peringatan Dini Banjir Berbasis Sensor Ultrasonik Dan Mikrokontroler Sebagai Upaya Penanggulangan Banjir. Jurnal Meteorologi Klimatologi Dan Geofisika, 4(2), 35-41. 